\title{
The Implementation of SNB Monetary Policy*
}

\author{
Thomas Jordan \\ Angelo Ranaldo \\ Swiss National Bank \\ Swiss National Bank \\ Paul Söderlind ${ }^{\dagger}$ \\ University of St. Gallen
}

29 July 2009

Forthcoming in Financial Markets and Portfolio Management

${ }^{*}$ The views expressed herein are those of the authors and not necessarily those of the Swiss National Bank (SNB). The SNB does not accept any responsibility for the contents and opinions expressed in this paper.

${ }^{\dagger}$ Thomas Jordan, Swiss National Bank, Member of the Governing Board, Börsenstrasse 15, P.O. Box 2800, Zurich, Switzerland. Angelo Ranaldo, Swiss National Bank, Research, Börsenstrasse 15, P.O. Box 2800, Zurich, Switzerland. E-mail: angelo.ranaldo@snb.ch. Paul Söderlind, University of St. Gallen, SBF, Rosenbergstrasse 52, CH-9000 St. Gallen, Switzerland. E-mail: Paul.Soderlind@unisg.ch. We thank Carlos Lenz for an insightful discussion in the early stages of this paper, and Marlène Amstad, Petra Gerlach and Enzo Rossi for their comments. 


\title{
The Implementation of SNB Monetary Policy
}

\begin{abstract}
We use a regime-switching approach to model the implementation of SNB monetary policy. The regime-switching technique is crucial for assessing the flexibility inherent in the SNB's monetary policy strategy. The empirical findings support the idea that repo operations are instrumental in smoothing the implementation of monetary policy in normal times, while changes in the official operational target accompanied by the accommodating use of repo operations produce the intended effects in periods of distress. A significant contribution also comes from some new measures designed to improve liquidity in the Swiss franc money market during the financial crisis of 2007-8.
\end{abstract}

Keywords: Implementation of monetary policy; Libor; repo; Swiss franc money market; regime switching model

JEL Classifications: E5, G15. 


\section{Introduction}

Central banks deploy different mechanisms to implement their monetary policy. The recent market turmoil has highlighted the way in which differing tools can give rise to completely different outcomes, in particular in terms of shortterm interest rate patterns ${ }^{1}$ During the financial market crisis, the ability of the Swiss National Bank (SNB) to stabilise its target rate has been observed with much interest by many specialists. For instance, in its Survey magazin $2^{2}$ the International Monetary Fund pointed out that "(T)he Swiss (monetary) approach imparts a degree of flexibility, which has served it well during the turbulence in financial markets." Probably the most noticeable characteristic of the SNB's monetary strategy is the balance between its long-term objective of price stability and the pragmatic short-term flexibility of its implementation mechanism. The intellectual background to this combination is discussed in Baltensperger, Hildebrand and Jordan (2007). The former property, i.e. a firm long-term anchor for nominal stability, has assured stable prices, which are an important prerequisite for the smooth functioning of the economy. The latter property, i.e. short-term flexibility in policy implementation, has two aspects. First, it assures regular functioning of liquidity provision in normal times and a swift response to exogenous shocks to the financial market. Second, it is an effective tool for achieving the intended policy stance in turbulent times.

The objective of this paper is twofold. First, we propose an econometric representation that captures the main characteristics of the SNB implementation mechanism. An antecedent in the literature is Jordan and Kugler (2004). Our model differs from that of Jordan and Kugler in a number of respects. First of all, it takes account of the official operational target, which is a range for the three-month Swiss franc Libor. A second feature is the fact that it incorporates the crucial role of SNB repo transactions, which provide the banking system with liquidity. A distinguishing characteristic of this dual mechanism in monetary policy implementation is its adaptability in stress periods. We capture this feature in a regime-switching model, where the regime mechanism depends on the tightness of money market conditions. Conceptually, the state dependency of the model ties in with the flexibility of the SNB's monetary policy strategy. Second, we analyse how the market has reacted to monetary policy decisions and to new funding facilities introduced by the SNB to tackle the financial crisis in 2007-2008. In particular, we investigate whether the announcement

\footnotetext{
${ }^{1}$ Hildebrand (2006) provides an in-depth discussion about the linkages between financial markets and monetary policy.

${ }^{2}$ See Ross (2008).
} 
and provision of US dollar funding to the Swiss money market, Swiss franc liquidity to the Eurosystem as well as unscheduled decisions about the SNB target range were associated with significant effects on the three-month Libor.

The structure of the remaining part of the paper is as follows: In section 2 we review the main characteristics of the SNB monetary strategy and its repo operations, and in section 3 we explain the empirical setup. Section 4 contains the empirical results. Section 5 concludes.

\section{The monetary policy strategy and its repo op- erations}

In this section, we briefly review the main characteristics of the SNB's monetary policy strategy and the Swiss franc repo market. More comprehensive contributions on the strategy can be found in Jordan and Peytrignet $(2001,2007)$ and Meyer (2000). Veyrassat (2001, 2004) and Kraenzlin (2007) provide more detailed descriptions of repo operations. We also briefly survey the new measures taken by the SNB to steer the money market during the financial crisis in 2007-2008. A more detailed presentation can be found in a text box published in the SNB Quarterly Bulletin, Q4 2008 (SNB, 2008).

\subsection{The monetary policy strategy}

At the end of 1999, the SNB abandoned the monetary targeting approach. Its new monetary policy framework is characterised by three main elements: (1) an explicit definition of price stability; (2) a conditional inflation forecast as the main indicator for future policy decisions; (3) a range for the threemonth Libor as operational target. The overriding objective of price stability is considered to be achieved with an inflation rate, measured by the national consumer price index, of less than $2 \%$ per annum. An inflation forecast for the following 12 quarters which takes into account all relevant information is the main indicator for policy decisions. The first two elements are complemented by the announcement of a target range for the three-month Swiss franc Libor. As documented in SNB (1999), the main reasons for choosing an off-shore market rate are the following: the Libor is the common money market rate, it is sensitive to all shocks relevant for monetary policy, and, by its very nature, it differs from repo rates, i.e. unlike a repo operation, the Libor represents the indicative rate of 'unsecured' interbank loans, which can give rise to liquidity and credit premia.

To understand the relevance of the last point, it is worth emphasising the 
different implications of targeting 'secure' and 'unsecure' interest rates. The Libor represents the short-term interest rate at which banks lend money to each other without posting collateral. Hence, it is an unsecure interest rate since the lender bears credit and liquidity risks. The related risk premia can increase substantially during financial crises, as has been witnessed since the outbreak of the financial crisis in August 2007. By contrast, repos are loans backed by securities. Thus, the repo rate is virtually free of risk. By targeting a range for the Libor, the SNB automatically takes into account the actual borrowing cost on the money market that includes risk premia and that ultimately determines the cost of borrowing in a broader sense (i.e. mortgages, corporate debts or derivative pricing).

\subsection{Repo market}

A repo transaction is a loan secured by collateral. The cash taker sells securities to the cash provider and repurchases them after an agreed period. The cash taker pays the cash provider a repo rate depending on the maturity of the transaction. The Swiss franc repo market can be divided into two main parts, namely the SNB repo market, characterised by transactions between the SNB and banks, and the repo interbanking market.

The SNB provides the banks with liquidity via repo transactions on a daily basis. Repos are auctioned in the morning in a fixed tender (as a rule) or are concluded in the course of the day on a bilateral basis. The liquidity provided is credited to non-interest-bearing sight deposits which the banks keep with the SNB. In normal times, the demand for sight deposits is determined by payment transactions, by the need for precautionary balances, and by the minimum reserve requirements stipulated in the National Bank Act ${ }^{3}$ According to these provisions, the banks must cover certain short term liabilities with coins and banknotes denominated in Swiss francs as well as sight deposits held with the SNB. The liquidity provided by the SNB is then traded on the interbank market. Interest rates on the money market are thus influenced by the price and volume of the liquidity injected by the SNB. In other words, the SNB indirectly steers the Libor by fixing rates and the amount to be allotted in the repo transactions.

\footnotetext{
${ }^{3}$ Foreign banks are not required to fulfil the minimum reserve requirements rule. The main reason for participation of foreign banks in repo auctions of the SNB is to refinance loans denominated in Swiss francs.
} 


\subsection{New measures during the financial crisis in $2007-2008$}

Like other central banks, the SNB has tackled the crisis by resorting to three main measures: unscheduled monetary decisions, repo transactions in US dollars and a swap arrangement through which the ECB can access Swiss franc liquidity so it can provide Swiss franc funding to banks within its jurisdiction.

Monetary policy decisions: After a tightening stance from June 2004 to September 2007, when the midpoint of the target range for the three-month Libor was raised from $0.25 \%$ to $2.75 \%$, the SNB kept the target range unchanged at 2.25-3.25\% from mid-September 2007 to mid-September 2008. Facing a rapid deterioration in the global economic outlook and a drop in inflation, the SNB undertook an unprecedented relaxation of monetary policy, with four consecutive cuts in the target range in a very short period, from 8 October to 11 December 2008. The monetary policy assessments on 6 October, 11 November and 20 November 2008 were all unscheduled. During this period, the midpoint of the target range was reduced by 1.75 percentage points. At the scheduled assessment in mid-December, the SNB cut its target range by a further 50 basis points, to reach $0.50 \%$.

US dollar funding: This new facility was designed to facilitate US dollar funding of SNB counterparties in the Swiss repo system. On 12 December 2007, the SNB announced the first provision of such funding. It was jointly introduced with the Bank of Canada, the Bank of England, the European Central Bank (ECB) and the Federal Reserve (Fed). The first operation took place on 17 December 2007, when the SNB offered US dollar repo transactions for a maximum amount of USD 4 billion, in addition to its Swiss franc open market operations. The dollar repo transaction against collateral eligible for SNB repos was conducted in the form of a variable-rate tender auction, and it provided funds for 28 days, with settlement on 20 December 2007. To back these operations, the SNB concluded a reciprocal swap agreement (swap line) with the Fed. A second operation was announced on 10 January 2008 and was implemented on 14 January. In a joint statement with the G10 central banks, the SNB announced on 11 March 2008 its intention of holding US dollar repo auctions for as long as was necessary. The characteristics of this facility changed during the year. In particular, the frequency was increased, as were the maturities and the maximum amount offered.

Swiss franc funding: Foreign banks in the euro area with no direct access to SNB operations exerted an upward pressure on short-term Swiss franc money market rates. On 15 October 2008, the SNB and the ECB (Eurosystem) jointly announced their intention of conducting EUR/CHF foreign exchange swaps, 
with the aim of providing Swiss francs against euro for a term of 7 days, at a fixed price. The operations took place each Monday, starting on 20 October 2008. To back these operations, the SNB and the ECB entered into a temporary swap arrangement, through which the ECB could access Swiss franc liquidity which it could provide to banks in its jurisdiction. On 7 November 2008, the SNB and the Polish central bank (National Bank of Poland, NBP) announced their cooperation for the provision of Swiss franc liquidity through the establishment of a temporary EUR/CHF swap arrangement. On 28 January 2009, a similar initiative was announced together with the Hungarian central bank (Magyar Nemzeti Bank, MNB). This new facility is similar to the existing one with the SNB and the ECB. The rationale was to allow the NBP and the MNB to offer Swiss franc funding to banks in their jurisdictions in the form of foreign exchange swaps.

\section{Empirical Setup}

\subsection{Economic explanation}

The implementation of the SNB's monetary policy strategy is based on two main elements: a decision about which part of the target range (upper half, centre or lower half) it is targeting, and a decision on the volume of repo transactions. According to the expectations hypothesis, monetary policy surprises, rather than actual changes in the central bank's target rate, should have an impact on asset prices. Thus, following Kuttner (2004), we compute a measure of surprise target rate changes by using the nearest-to-maturity futures contracts on the Swiss franc three-month Libor. In order to enhance measurement precision and minimise endogeneity problems, we measure the price change over 30 minutes, i.e. 10 minutes before and 20 minutes after the exact release time of a monetary policy decision 4 We call this variable $\operatorname{surpr}_{t}$. The repo operations are represented by the one-week repo rate on day $t$, repo $_{t}$ (its difference is denoted $\Delta$ repo $_{t}$ ) and the allotted volume in the morning auctions. We compute the allotment ratio (i.e. allotted volume divided by bid volume) and call it allotratio $t^{5}$ The intraday data set necessary to compute the monetary policy surprise and the data on the repo operations are taken from the SNB ${ }^{6}$

\footnotetext{
${ }^{4}$ For further information about the timing and surprise effect of SNB monetary policy assessments, cf. Ranaldo and Rossi (2007).

${ }^{5}$ In the morning auction, the SNB adds up all bids and decides the proportion to be allotted. Normally, it allots on a pro rata basis, i.e. after a minimal allotment to each bank, the remaining demand is accommodated in percentage of the amount bid.

${ }^{6}$ We are grateful to Marcel Zimmermann for providing us the dataset.
} 
The Libor moves in accordance with credit conditions in the money market. However, the flexibility of the SNB strategy means that it can react to unexpected events. To take account of these features, our empirical model allows the Libor to move and react differently in two kinds of regimes: those characterised by normal markets, and those characterised by distressed markets. Empirically, the regime depends on the tightness of money market conditions, which is proxied by the standardised spread (with zero mean and unit variance) between the Libor and repo rates, denoted $z_{t}$. This spread can be seen as a broad measure of risk premia on interbank lending. In troubled times, this spread typically widens.

Other factors can determine the movement of the Libor. There can be some exogenous variables that correspond to the market factors that the SNB may take into account when fixing its morning repo rates, but that are outside its control. Below, we limit the empirical analysis to the VIX index, i.e. vix $t^{7}$

The remaining variables capture the new funding facilities introduced by the SNB in the wake of the financial crisis. We use information publicly available to set up a dataset containing the announcement and implementation days of the US dollar and Swiss franc funding auctions. Below, we focus on a dummy variable, called $\operatorname{swap}_{t}$, which equals 1 when a CHF funding auction takes place and 0 otherwise.

\subsection{Econometric model}

Our regime-switching technique models the coefficients as changing smoothly with the regime variable that we generally call $z$. In practice, this means that the coefficient of a regressor is

$$
b(z)=[1-G(z)] b_{1}+G(z) b_{2}
$$

where $G(z)$ is a logistic function $G(z)=1 /[1+\exp (-3(z-c))]$. When $z$ (the standardised Libor-Repo spread) is low, then the effective slope is $b_{1}$; when $z=c$, then the slope is $\left(b_{1}+b_{2}\right) / 2$; and with a very high $z$ the slope is effectively $b_{2}$. This function is illustrated in Figure 1 (using the value of $c$ estimated below).

The formation process of the Libor can be structured as follows:

$$
\begin{aligned}
\Delta_{\text {libor }_{t}} & =\phi \Delta \text { libor }_{t-1}+\delta\left(z_{t-1}\right) \text { surpr }_{t}+\chi\left(z_{t-1}\right) \Delta \text { repo }_{t} \\
& + \text { qullotratio } \\
& +\psi \text { swap }_{t}+\lambda v i x_{t-1}+\alpha+\varepsilon_{t}
\end{aligned}
$$

${ }^{7}$ All other variables we considered, such as the overnight volatility on the exchange rate market, were insignificant. 
This equation means that changes in the Libor can be due to five main drivers. First, it can be affected by unexpected changes in the official target range, i.e. surpr $_{t}$. We carefully considered the timing of the news releases. When the SNB announces its decision on the target range for the Libor before (after) the Libor rate fixing, i.e. at noon CET, the decision is assumed to impact on the Libor rate on the day (day after). Second, the Libor might respond to

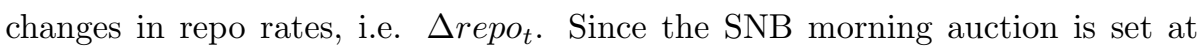
9:10 CET, we consider the effects of the repo operations on the same day of the Libor fixing. The coefficients on these two variables are allowed to change with the regime variable (the standardised Libor-repo spread, lagged one day) as illustrated in equation (1).

Third, a broader provision of liquidity should decrease the Libor. We attempt to capture this effect by looking at the volume allotted at the morning

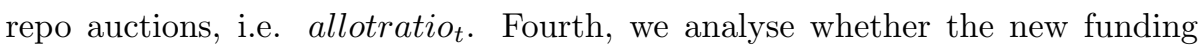
facilities had some bearing on the Libor rates. In the equation above, we take the representative case of the implementation of Swiss franc funding provided by the Eurosystem, i.e. $\operatorname{swap}_{t}$. However, we also inspect the implementation and announcement effects of the US dollar funding. Fifth and finally, the VIX index, i.e. vix $x_{t-1}$, is a proxy for exogenous variables. These three last variables in equation (2) are not allowed to change with the regime - as preliminary regressions indicated that the coefficients related to allotratio $t$ and vix $x_{t-1}$ do not change significantly across regimes and Swiss franc funding auctions took place only in the high regime (e.g. swapt $_{t}$ ).

We estimate the parameters by GMM (actually, nonlinear least squares) and the t-stats account for heteroskedasticity and autocorrelations. In total, there are 9 parameters ( $c$ in (1), and $\delta_{1}, \delta_{2}, \chi_{1}, \chi_{2}, \varphi, \psi, \lambda, \alpha$ in (2)).

\subsection{Limitations}

It is worth emphasising some limitations of the model presented above.

In particular, repo conditions have changed over time. In mid-August 2007 (i.e. at the beginning of the credit crunch) the SNB expanded the list of collateral eligible for repo transactions 8 On 16 October 2008, the SNB introduced a special purpose vehicle (SPV) as a form of long-term financing to support the Swiss financial sector, and in particular, to perform an orderly liquidation of illiquid securities and other troubled assets held by UBS. We checked whether the Libor reacted in any particular way on the day the SPV was announced.

\footnotetext{
${ }^{8}$ On 11 December 2008 and the day after, the SNB offered one-year Repo contracts at the same rate of the one-week repo. There was little demand for longer repo maturities.
} 
This simple, ad hoc event study analysis rejected this hypothesis . A final possible shortcoming of our study is related to the introduction of SNB Bills, an instrument to absorb liquidity, on 15 October 2008. Again, a simple event study analysis shows no particular effect on the announcement day.

We considered several alternative specifications of the model. In particular, we analysed a bivariate VAR model in a regime-switching setting, where the first equation features the Libor dynamics and the second equation, the repo rates. We also carried out an analysis in which the regime mechanism was treated as dependent on the spread between the Libor and the Overnight Index Swap (OIS) rates, rather than that between the Libor and repo rates. These alternative models deliver the same picture as the results presented below. We also considered error correction mechanisms between the Libor and repo rates, the actual changes in the midpoint target range in addition to the monetary surprise, as well as one or more lags for the regressors and auto-regressive terms. All of these turned out to be insignificant. It is also worth noting that our results are not sensitive to the specific parameter 3 in the logistic function. We obtained similar results when this parameter was replaced by any figure from one up to very large positive numbers.

\section{Empirical findings}

The empirical analysis is based on daily data from January 2000 to the end of 2008. Figure 2 shows the behaviour of the regime variable $\mathrm{z}$ (the standardised Libor-repo spread) over time. The high regime occurs mostly at the end of the sample period. The estimated location parameter of the logistic function $(c$, estimated to be 1.358) is indicated by the horisontal dashed line. By comparing with the shape of the logistic regime function in Figure 1, we see that the period 2001 to mid 2007 clearly belongs to the 'low regime', the second half of 2007 is an intermediate case, while most of 2008 belongs to the 'high regime' (with particularly high values after Lehman's bankruptcy filing).

Table 1 shows the main results. The upper part of the table shows the estimated coefficients and the related t-statistics that remain unchanged across regimes. In some cases, the regime dependence of these regressors was insignificant in preliminary regressions (not shown) and in others, they were implemented only in the high regime (e.g. swap $_{t}$ ). The second panel of the table reports the estimate for the standardised value of $c$ of the logistic function. At the left-hand (right-hand) side of the third panel of the table we report the estimated coefficients and t-statistics in normal (distressed) times, which we refer 
to as the 'low regime' ('high regime'). The fourth panel shows the changes in the estimated coefficients between the two regimes. Low-regime (high-regime) days occurred 2084 (263) times.

Two main results emerge from our analysis. First, the Libor reacts very differently to repo and target-range changes in the two regimes. In normal times (low regime), the repo rate appears to be the main driver. The Liborrepo rate link has the biggest effect, i.e. a change of 25 basis points in the one-week repo rate translates, on average, into a change in the Libor of 5 basis points. This finding suggests that market participants scrutinise the SNB repo operations to understand its monetary policy stance which, in turn, affords a smooth implementation of monetary policy. However, during a crisis, an unexpected change in the target range is extremely effective in determining the Libor. An unanticipated lowering of the target range by 25 basis points implies, on average, a decrease in the Libor by 30 basis points 9

Second, three variables play a significant role, regardless of the regime. We find that the new Swiss franc funding facility in the Eurosystem had a significant effect in reducing the Libor. Moreover, favourable effects also came from the repo operations of the morning auctions, which play an auxiliary role in implementing a monetary policy decision. Accordingly, a larger allotment of liquidity leads to a decrease in the Libor. Finally, a high VIX index value is associated with a lower Libor. The main explanations for this link are that (1) during the tightening phase from mid-2004 to mid-2007, stock market volatility was relatively low, and (2) the Swiss franc tends to appreciate when volatility is high ${ }^{10}$, which may require a counterbalancing interest rate move in order to preserve price stability in the medium term.

\section{Conclusion}

We use a regime-switching approach to model implementation of the SNB's monetary policy. A regime-switching technique is crucial for assessing the flexibility inherent in its monetary policy strategy. The empirical findings support the idea that repo operations are instrumental in smoothing the monetary policy stance in normal times, whereas (unexpected) decisions on the official operational target accompanied by a larger liquidity provision in repo operations produce the targeted effects during distressed periods. Also, there is empirical evidence that

\footnotetext{
${ }^{9}$ One could raise the question whether monetary policy surprises are more effective in turbulent times since there are more. Our specification should be seen as free of this problem since we control for the regime.

${ }^{10}$ See the safe haven effects of the Swiss franc analysed by Ranaldo and Söderlind (2007)
} 
the new facility designed to ease funding problems in the Swiss franc money market has had the intended effects. 


\section{References}

[1] Baltensperger, Ernst, Philipp M. Hildebrand, Thomas J. Jordan (2007), The Swiss National Bank's monetary policy concept: an example of a 'principles-based' policy framework, Swiss National Bank, Economic Study \#3.

[2] Hildebrand, Philipp M. (2006). Monetary policy and financial markets. Financial Markets and Portfolio Management 20(1): 7-18.

[3] Jordan, Thomas J. and Peter Kugler (2004). Implementing Swiss monetary policy: steering the 3-month Libor with repo transactions. Schweizerische Zeitschrift für Volkswirtschaft und Statistik 140(3), 381-393.

[4] Jordan, Thomas J. and Michel Peytrignet. 2001. Die Inflationsprognose der Schweizerischen Nationalbank (The inflation forecast of the Swiss National Bank). Swiss National Bank Quarterly Bulletin 2, June: 54-61.

[5] Jordan, Thomas J. and Michel Peytrignet, 2007. The path to interest rate management and inflation forecasts, In The Swiss National Bank, 19072007, Swiss National Bank, ed., 255-272. Zurich: Neue Zürcher Zeitung Publishing.

[6] Kraenzlin, S. (2007). The characteristics and development of the Swiss franc repurchase agreement market. Financial Markets and Portfolio Management 21: 241-261.

[7] Kuttner, K. N. (2001). "Monetary Policy Surprises and Interest Rates: Evidence from the Fed Funds Futures Market", Journal of Monetary Economics $47(3), 523-544$.

[8] Meyer, Hans. 2000. Zur Geldpolitik im Neuen Jahr. Speech at the University of St Gallen, 20 January. http://www.snb.ch/de/mmr/speeches /id/ref_20000120_m/source/ref_20000120_m.de.pdf

[9] Ranaldo, Angelo and Enzo Rossi (2007). The reaction of asset markets to Swiss National Bank communication, SNB Working Paper 2007-11.

[10] Ranaldo, Angelo and Paul Söderlind (2007). Safe haven currencies, SNB Working Paper 2007-17.

[11] Ross, Kevin (2008). Distinctive Swiss Monetary Framework Shields Real Economy. International Monetary Fund Survey Magazine, July 16, 2008. 
Available on:

http://www.imf.org/external/pubs/ft/survey/so/2008/CAR071608A.htm

[12] Swiss National Bank (1999), Monetary policy decisions of the Swiss National Bank for 2000, Swiss National Bank Quarterly Bulletin 4.

[13] Swiss National Bank (2008), Monetary Policy Report, Swiss National Bank Quarterly Bulletin 4.

[14] Veyrassat, A. (2001). Steuerung der Geldmarktsätze durch die Schweizerische Nationalbank. Financial Markets and Portfolio Management 15: 344-362.

[15] Veyrassat, A. (2004). The Swiss franc money market: instruments and market participants. Swiss National Bank Quarterly Bulletin 3, June: 4255 . 


\begin{tabular}{|c|c|c|c|c|}
\hline $\begin{array}{l}\text { Regime-independent regressors } \\
\text { constant } \\
\text { vix } x_{t-1} \\
\text { swap } \\
\text { allotratio }\end{array}$ & $\begin{array}{r}\text { coeff } \\
0.008 \\
-0.032 \\
-0.015 \\
-0.004 \\
\end{array}$ & $\begin{array}{r}\text { t-stat } \\
7.503 \\
-5.242 \\
-1.945 \\
-2.831 \\
\end{array}$ & & \\
\hline $\begin{array}{l}\text { Logistic function } \\
c\end{array}$ & $\begin{array}{r}\text { coeff } \\
1.358\end{array}$ & $\begin{array}{r}\text { t-stat } \\
1.989\end{array}$ & & \\
\hline & \multicolumn{2}{|c|}{ Low Regime } & \multicolumn{2}{|c|}{ High Regime } \\
\hline $\begin{array}{l}\text { Regime-dependent regressors } \\
\Delta \text { repo } \\
\text { surpr }\end{array}$ & $\begin{array}{r}\text { coeff } \\
0.217 \\
0.411\end{array}$ & $\begin{array}{r}\text { t-stat } \\
4.210 \\
3.200\end{array}$ & $\begin{array}{r}\text { coeff } \\
-0.064 \\
1.283\end{array}$ & $\begin{array}{r}\text { t-stat } \\
-1.001 \\
14.185\end{array}$ \\
\hline $\begin{array}{l}\text { Difference between regimes } \\
\Delta \text { repo } \\
\text { surpr }\end{array}$ & $\begin{array}{r}\text { coeff change } \\
-0.280 \\
0.872\end{array}$ & $\begin{array}{r}\text { t-stat } \\
-3.285 \\
5.539\end{array}$ & & \\
\hline $\begin{array}{l}R^{2} \\
\text { Number of observations }\end{array}$ & $\begin{array}{r}0.39 \\
2347.00\end{array}$ & & & \\
\hline
\end{tabular}

Table 1: Estimates from the regime-switching model. This table shows the estimated coefficients and t-statistics from the regime-switching model. The first panel refers to the regressors that remain unchanged across regimes. The second panel reports the estimate for the normalised value of $\mathrm{c}$ of the logistic function. The third panel reports results on regressors whose coefficients differ between regimes: on the left-hand (right-hand) side we report the estimated coefficients and t-statistics in normal (distressed) times, which we refer to as 'low-regime' ('high-regime'). The fourth panel shows the changes in the estimated coefficients and t-statistics between 'low regime' and 'high regime' for the three regime-dependent regressors. The last panel reports the coefficient of determination and the number of observations. 


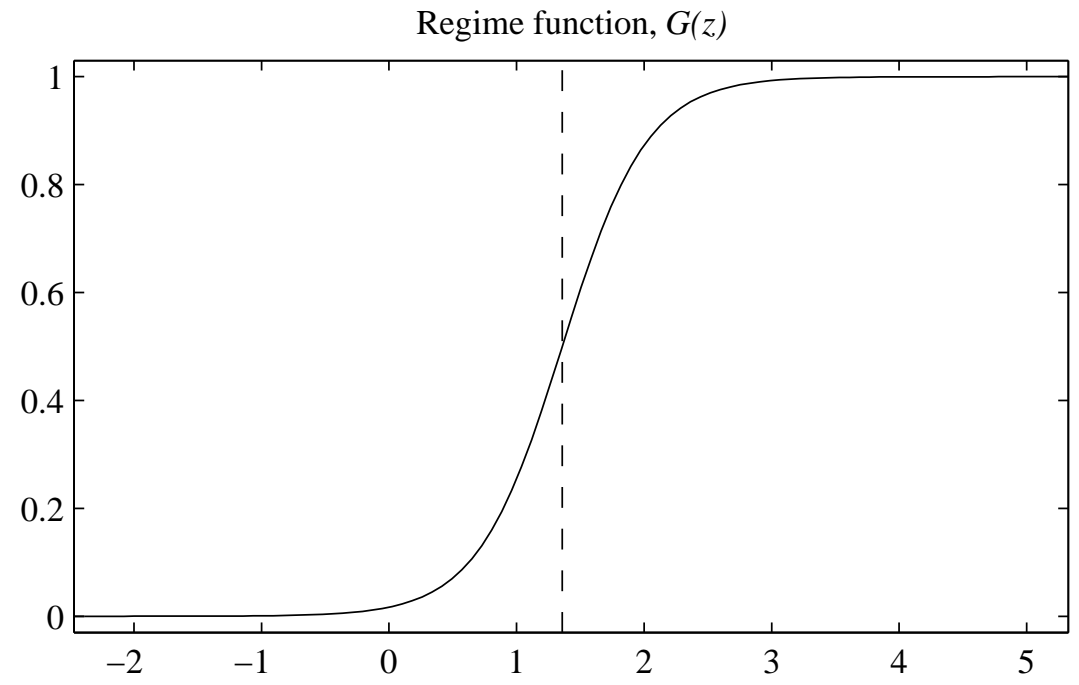

Figure 1: Estimated regime function

Regime variable $(z)$

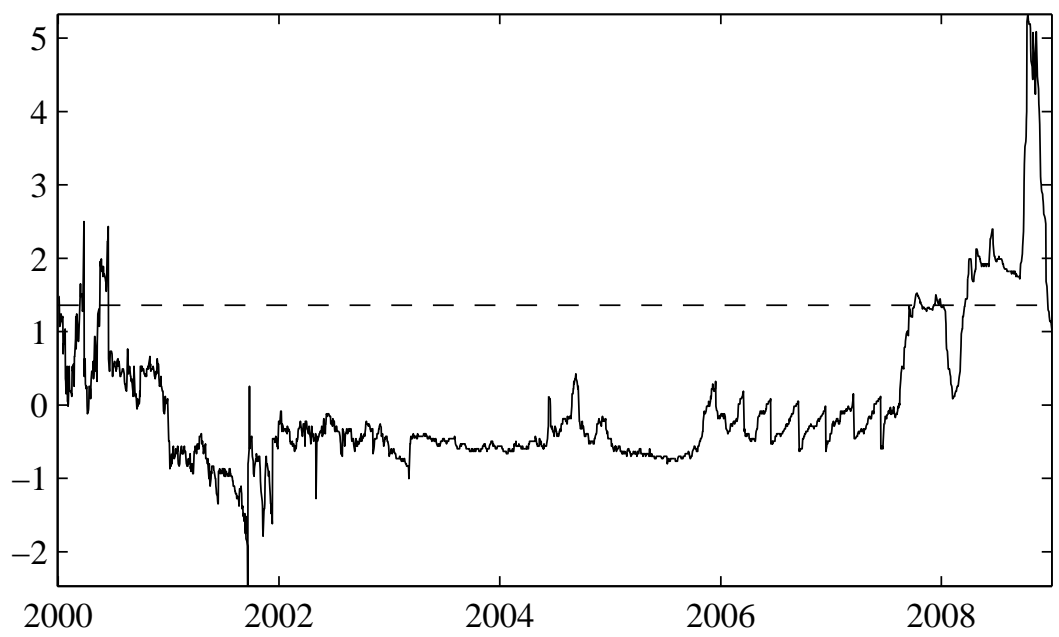

Figure 2: Regime variable (standardised Libor - repo spread) 